\title{
Reproducibility of 6-minute walking test in patients with COPD
}

\author{
N.A. Hernandes ${ }^{*, \#, \uparrow,+, \text { E.F.M. Wouters }}{ }^{*, \varsigma}$, K. Meijer ${ }^{f}$, J. Annegarn ${ }^{f}$, \\ F. Pitta ${ }^{\#, \uparrow}$ and M.A. Spruit*
}

ABSTRACT: The reproducibility of the 6-min walking test (6MWT) needs to be more solidly studied. This study aimed to investigate the reproducibility of two 6MWTs performed on subsequent days in a large and representative sample of patients with chronic obstructive pulmonary disease (COPD), and to quantify the learning effect between the two tests, as well as its determinants.

In a retrospective observational study, 1,514 patients with COPD performed two 6MWTs on subsequent days. Other measurements included body composition (dual X-ray absorptiometry), dyspnoea (Medical Research Council scale) and comorbidity (Charlson index).

Although the 6MWT was reproducible (intraclass correlation coefficient $=0.93$ ), patients walked farther in the second test $(391 \mathrm{~m}, 95 \% \mathrm{Cl} 155-585 \mathrm{~m}$ versus $418 \mathrm{~m}, 95 \% \mathrm{Cl}$ 185-605 $\mathrm{m} ; \mathrm{p}<0.0001)$. On average, the second 6MWT increased by $27 \mathrm{~m}$ (or $7 \%$ ), and $82 \%$ of patients improved in the second test. Determinants of improvement $\geqslant 42 \mathrm{~m}$ in the second test (upper limit of the clinically important change) were as follows: first 6MWT $<350 \mathrm{~m}$, Charlson index $<2$ and body mass index $<30 \mathrm{~kg} \cdot \mathrm{m}^{-2}$ (OR 2.49, 0.76 and 0.60 , respectively).

The 6MWT was statistically reproducible in a representative sample of patients with COPD. However, the vast majority of patients improved significantly in the second test by an average learning effect of $27 \mathrm{~m}$.

KEYWORDS: Chronic obstructive pulmonary disease, 6-min walking test, reproducibility of results

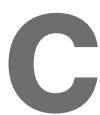

hronic obstructive pulmonary disease (COPD) is a systemic disease characterised by progressive airflow limitation, exercise intolerance and physical inactivity $[1,2]$. Although the degree of airflow obstruction is frequently used as a marker of disease severity, it does not adequately reflect extrapulmonary manifestations of COPD [3, 4]. Some modalities of field tests are available to assess these patients' exercise capacity [4], which better reflect the extrapulmonary features of the disease.

The 6-min walking test (6MWT) is a simple and inexpensive test that provides a global and integrated response of both physical (pulmonary and nonpulmonary factors) and psychological factors $[5,6]$. The $6 \mathrm{MWT}$ is used to assess functional exercise capacity before and after interventions $[7,8]$ and as a predictor of morbidity and mortality in COPD [9].

In general, the 6MWT is a reliable test in COPD patients but a learning effect has been suggested [10-15], i.e. patients achieving a considerably higher walked distance when a second test is

For editorial comments see page 244. performed. Indeed, there is controversy about the size of the learning effect, which may range from $2.6 \%$ to $22 \%$ [10, 11, 16-20]. Moreover, the external validity of the previous studies is limited due to the pre-specified inclusion criteria $[10,11,13,18]$. Furthermore, researchers usually used statistical analysis that did not demonstrate trends and agreement between both 6MWTs, thereby compromising the internal validity of the results [10]. Additionally, the determinants of improvement in walking distance remain unknown. Considering the importance of the 6MWT in clinical practice when assessing patients with COPD and in putting together exercise training programmes [21], its reproducibility and determining factors need to be more solidly studied.

Therefore, the aim of this study was, first, to investigate the reproducibility of the 6MWT in a large and representative sample of patients with COPD and to quantify the learning effect between two 6MWTs performed on subsequent days. Secondly, we intended to study the determining factors of changes in the second 6MWT.
AFFILIATIONS

*Program Development Centre, Centre of Excellence for Chronic Organ Failure (CIR0+) Horn, ${ }^{5}$ Maastricht University Medical Centre (MUMC+), Dept of Respiratory Medicine,

${ }^{f}$ Dept of Human Movement Science, Faculty of Health, Medicine and Life Sciences, Maastricht University, Maastricht, The Netherlands, " Laboratory of Research in Respiratory Physiotherapy (LFIP), Dept of Physiotherapy, Universidade Estadual de Londrina (UEL), +Universidade Norte do Paraná (UNOPAR), Londrina, and "Post-Graduate Program in Physiotherapy, Dept of Physiotherapy, Universidade Estadual Paulista - UNESP, Presidente Prudente, Brazil.

CORRESPONDENCE

N.A. Hernandes

Rua Borba Gato, 564 apt. 202

Vila Ipiranga CEP

86010-630

Londrina

Paraná

Brazil

E-mail: nyhernandes@gmail.com

Received:

Sept 042010

Accepted after revision:

Nov 262010

First published online:

Dec 222010 


\section{METHODS}

In a retrospective observational study, 1,683 patients with COPD were included. Data were collected from patients who were evaluated during the baseline assessment before entering a pulmonary rehabilitation programme at CIRO+ (Centre of Expertise for Chronic Organ Failure; Horn, the Netherlands) from January 2005 to August 2009. These retrospective analyses are institutional review board exempt due to the use of deidentified, pre-existing data.

Inclusion criteria were as follows: diagnosis of COPD according to criteria determined by the Global Initiative for Chronic Obstructive Lung Disease (GOLD) [1]; clinical stability (absence of exacerbations in the last 3 months); nonparticipation in rehabilitation programmes during the last 2 yrs; absence of unstable cardiac disease; and absence of neurological comorbidities that may limit 6MWT performance. 169 patients were excluded because they only performed one 6MWT. Therefore, 1,514 patients with stable COPD (59\% males) completed two 6MWTs and were included in the analyses (table 1).

\section{MWT}

Two 6MWTs were performed according to the guidelines of the American Thoracic Society [6] on subsequent days using a triangular walking course of $125 \mathrm{~m}$. The walking tests were executed by a physiotherapist or a biometrist who walked behind the patient. Patients were instructed to walk as fast as they could and the distance walked was registered after 6 min. During the test, standardised encouraging phrases were given to patients each minute. Patients who used walking aids in daily life were allowed to use the devices during the $6 \mathrm{MWT}$. Cardiac frequency $(f \mathrm{C})$, arterial oxygen saturation as measured by pulse oximetry $\left(S_{\mathrm{p}}, \mathrm{O}_{2}\right)$, perceived dyspnoea and leg fatigue (modified Borg scale) were assessed before and after the 6MWTs. Oxygen supplementation was used if required, and oxygen desaturation during the 6MWT was defined as the difference between end and beginning $S_{\mathrm{p}, \mathrm{O}_{2}}$ of $\geqslant-4 \%$ and/or an end $\mathrm{Sp}_{\mathrm{p}} \mathrm{O}_{2}$ of $<88 \%$ [15]. Reference values for delta of Borg score and $f C$ were those from VAN STEL et al. [22] and for 6MWT were those from TroOsters et al. [23].

\section{Lung function}

Spirometry (Masterlab ${ }_{\circledR}$; Jaeger AG, Würzburg, Germany) was performed according to the European Respiratory Society recommendations [24] and reference values were those from KNUDSON et al. [25]. Lung function parameters used for analysis were forced expiratory volume in $1 \mathrm{~s}$ (FEV1) and forced vital capacity (FVC).

\section{Body composition}

A total body scan was performed by whole-body dual energy X-ray absorptiometry using a Lunar Prodigy system (GE Healthcare, Piscataway, NJ, USA) as described previously [26]. Fat-free mass (FFM) was provided from the sum of lean and mineral bone mass. The FFM index (FFMI) was calculated as FFM (kg) divided by height squared $\left(\mathrm{m}^{2}\right)$ [27]. The body mass index (BMI) was calculated as body weight $(\mathrm{kg})$ divided by height squared $\left(\mathrm{m}^{2}\right)$.

\section{Functional limitation due to dyspnoea}

The Medical Research Council (MRC) scale was used to evaluate the level of functional limitation due to breathlessness in activities of daily living [3].

\section{BODE index}

The body mass index, airflow obstruction, dyspnoea and exercise capacity (BODE) index is a multidimensional grading system used as a predictor of risk of death in COPD patients and as an outcome reflecting disease severity. The index was calculated according to CELLI et al. [28].

\section{Comorbidities}

The presence of comorbidities was evaluated using the Charlson index. It is composed of 19 categories of comorbidities and the total score reflects the cumulative increased likelihood of 1-yr mortality [29]. A higher score indicates more severe burden of comorbidities.

\section{Statistical analysis}

Statistical analysis was performed using the statistical packge SPSS 17.0 (SPSS Inc., Chicago, IL, USA) and GraphPad Prism 5 (GraphPad Software Inc., La Jolla, CA, USA). Data were described as mean $\pm \mathrm{SD}$. The intra-class correlation coefficient was used to verify the reproducibility of the 6MWT. The Bland and Altman plot was used to evaluate trend and agreement between first and second tests and, additionally, the paired t-test was used to compare outcome parameters between the two tests. Unpaired t-test and one-way ANOVA (post hoc Tukey) were used to compare patient characteristics between different groups. Ordinal data were analysed using nonparametric tests. Logistic regression assessed determinant factors of a clinically important change in walked distance between the first and second tests $(\geqslant 42 \mathrm{~m}$ [7]). A p-value of $\leqslant 0.05$ was considered to be statistically significant for all.

\section{RESULTS}

\section{Characteristics}

In general, patients presented with moderate-to-very severe COPD. $24 \%$ of patients used ambulatory oxygen therapy, $32 \%$ used rollators and $1.3 \%$ used canes. The majority of patients $(60 \%)$ had an abnormal BMI (low, overweight or obese), whereas 30\% had an abnormally low FFMI. Moreover, $18 \%$ of patients had Charlson index $>2$ points, and $97 \%$ scored grade 2 or higher on the MRC dyspnoea scale. Males were older than females, presenting with lower FEV1 and FVC, higher inspiratory capacity, lower MRC dyspnoea grade and higher FFMI (table 1).

\section{Reproducibility of the 6MWT}

On average, patients walked $391 \mathrm{~m}$ (95\% CI 155-585 m) in the first 6MWT and $418 \mathrm{~m} \mathrm{(95 \%} \mathrm{CI} \mathrm{185-605} \mathrm{m)} \mathrm{in} \mathrm{the} \mathrm{second}$ $6 \mathrm{MWT}$. The distance walked in the second test increased on average by $27 \mathrm{~m}(95 \% \mathrm{CI}-37-107 \mathrm{~m}) .35 \%$ of the patients had a poor first $6 \mathrm{MWT}(<350 \mathrm{~m})$. This proportion of poor walkers decreased in the second $6 \mathrm{MWT}$ to $28 \%$.

$82 \%$ of patients with COPD walked farther during the second $6 \mathrm{MWT}$. In fact, $28 \%$ of the subjects increased their walked distance by $>42 \mathrm{~m}$, which is currently the upper limit of change considered to be an important treatment effect [7]. 


\begin{tabular}{|c|c|c|c|}
\hline \multirow[t]{2}{*}{ TABLE 1} & \multirow[b]{2}{*}{ COPD patients } & \multirow{2}{*}{ Male } & \multirow[b]{2}{*}{ Female } \\
\hline & & & \\
\hline Patients $\mathrm{n}$ & 1514 & 888 & 626 \\
\hline Age yrs & $64 \pm 10$ & $66 \pm 9$ & $62 \pm 9^{\#}$ \\
\hline BMI $\mathbf{k g} \cdot \mathbf{m}^{-2} \%$ & $25 \pm 5$ & $25 \pm 5$ & $25 \pm 6$ \\
\hline$<21$ & 16 & 14 & 20 \\
\hline $21-24$ & 40 & 40 & 42 \\
\hline $25-29$ & 28 & 31 & 24 \\
\hline$\geqslant 30$ & 16 & 15 & 14 \\
\hline FFMI $\mathbf{k g} \cdot \mathrm{m}^{-2} \%$ & $16 \pm 2$ & $17 \pm 2$ & $15 \pm 2^{\#}$ \\
\hline$<16$ & & 24 & \\
\hline$<15$ & & & 39 \\
\hline FEV $1 \%$ pred & $45 \pm 18$ & $44 \pm 17$ & $47 \pm 19^{\#}$ \\
\hline FVC \% pred & $92 \pm 23$ & $90 \pm 22$ & $95 \pm 24^{\#}$ \\
\hline Inspiratory capacity L & $3.04 \pm 0.97$ & $3.45 \pm 0.91$ & $2.46 \pm 0.73^{\#}$ \\
\hline GOLD I/II/III/IV \% & $5 / 31 / 44 / 20$ & $4 / 29 / 47 / 20$ & $6 / 35 / 38 / 21$ \\
\hline MRC dyspnoea scale grade & $4 \pm 1$ & $3 \pm 1$ & $4 \pm 1^{\#}$ \\
\hline MRC grade $\geqslant 2 \%$ & 97 & 97 & 98 \\
\hline BODE index points & $4 \pm 2$ & $4 \pm 2$ & $4 \pm 2$ \\
\hline LTOT \% & 24 & 22 & 26 \\
\hline Charlson index $1 / 2 />2 \%$ & $59 / 23 / 18$ & $53 / 26 / 22$ & $69 / 19 / 12$ \\
\hline Rollator \% & 32 & 28 & 37 \\
\hline Cane \% & 1.3 & 1.6 & 0.8 \\
\hline 6MWT T1 m & $391 \pm 127$ & $405 \pm 128$ & $372 \pm 124^{\#}$ \\
\hline 6MWT T2 m & $418 \pm 127^{\bullet}$ & $430 \pm 128$ & $399 \pm 122^{\#, 9}$ \\
\hline$\Delta 6 \mathrm{MWT} \mathrm{m}$ & $27 \pm 48$ & $26 \pm 51$ & $28 \pm 42$ \\
\hline Borg D baseline T1 points & $2.20 \pm 1.58$ & $2.26 \pm 1.55$ & $2.11 \pm 1.61$ \\
\hline Borg D baseline T2 points & $2.17 \pm 1.53$ & $2.20 \pm 1.56$ & $2.14 \pm 1.49$ \\
\hline$\Delta$ Borg D T1 points & $2.60 \pm 1.97$ & $2.55 \pm 1.95$ & $2.66 \pm 1.99$ \\
\hline$\Delta$ Borg D T2 points & $2.52 \pm 1.95$ & $2.47 \pm 1.98$ & $2.60 \pm 191$ \\
\hline Borg $F$ baseline $T 1$ points & $1.84 \pm 1.65$ & $1.86 \pm 1.66$ & $1.79 \pm 1.65$ \\
\hline Borg $\mathrm{F}$ baseline $\mathrm{T} 2$ points & $2.10 \pm 1.74^{\circ}$ & $2.17 \pm 1.76^{\bullet}$ & $2.00 \pm 1.69$ \\
\hline$\Delta$ Borg F T1 points & $1.98 \pm 1.93$ & $1.93 \pm 1.98$ & $2.05 \pm 1.84$ \\
\hline$\Delta$ Borg F T2 points & $2.01 \pm 2.02$ & $2.02 \pm 2.06$ & $1.99 \pm 1.96$ \\
\hline $\mathrm{Sp}, \mathrm{O}_{2}$ baseline $\mathrm{T} 1 \%$ & $94 \pm 2$ & $94 \pm 4$ & $95 \pm 5$ \\
\hline $\mathrm{Sp}, \mathrm{O}_{2}$ baseline T2 \% & $94 \pm 3$ & $94 \pm 4$ & $95 \pm 3^{\#}$ \\
\hline$\Delta S p, O_{2} T 1 \%$ & $-5.7 \pm 5.1$ & $-5.5 \pm 5.0$ & $-5.8 \pm 5.1$ \\
\hline$\Delta S_{p}, O_{2} T 2 \%$ & $-5.5 \pm 5.0$ & $-5.5 \pm 5.0$ & $-5.5 \pm 4.9$ \\
\hline$f c$ baseline $\mathrm{T} 1$ beats $\min ^{-1}$ & $86 \pm 16$ & $85 \pm 16$ & $87 \pm 16^{\#}$ \\
\hline$f c$ baseline $T 2$ beats $\min ^{-1}$ & $87 \pm 14$ & $85 \pm 15$ & $89 \pm 14^{\#}$ \\
\hline$\Delta f C \mathrm{~T} 1$ beats $\cdot \mathrm{min}^{-1}$ & $21 \pm 15$ & $22 \pm 15$ & $21 \pm 14$ \\
\hline$\Delta f \mathrm{C} 2$ beats $\mathrm{min}^{-1}$ & $22 \pm 14$ & $22 \pm 14$ & $21 \pm 14$ \\
\hline
\end{tabular}

Data are expressed as mean $\pm S D$, unless otherwise indicated. BMI: body mass index; FFMI: fat-free mass index; FEV1: forced expiratory volume in $1 \mathrm{~s}$; \% pred: \% predicted; FVC: forced vital capacity; GOLD: Global Initiative for Chronic Obstructive Lung Disease; MRC: Medical Research Council; BODE: body mass index, aiflow obstruction, dyspnoea and exercise capacity; LTOT: Iong-term oxygen therapy; T1: first test, T2: second test, Borg D: Borg dyspnoea scale; Borg F: Borg fatigue scale; $\mathrm{Sp}_{1} \mathrm{O}_{2}$ : arterial oxygen saturation as measured by pulse oximetry; fc: cardiac frequency. ${ }^{\#}$ : male versus female, $p<0.0001 ;$ ?: T1 versus $\mathrm{T} 2, \mathrm{p}<0.0001$ for all.
Conversely, $6 \%$ of COPD patients decreased their walked distance by $>42 \mathrm{~m}$ in the second test.

Rollator users tended to have a higher change than nonrollator users (mean \pm SD $30 \pm 51$ versus $25 \pm 46 \mathrm{~m}$, respectively; $\mathrm{p}=0.058$ ). No difference was observed when comparing the changes in walked distance between male and female subjects $(26 \pm 51$ versus $28 \pm 42 \mathrm{~m}$, respectively; $\mathrm{p}>0.05$ ). A similar proportion of males and females increased their walked distance in the second test ( $81 \%$ versus $83 \%$, respectively). Furthermore, no difference was observed when comparing the changes in walked distance among GOLD stages I, II, III and IV $(26 \pm 38,24 \pm 48,27 \pm 45$ and $26 \pm 49 \mathrm{~m}$, respectively; $\mathrm{p}>0.05$ ).

The Bland and Altman plot confirms that patients increased the distance walked in the second test (fig. 1). Indeed, statistically the 6MWT was reproducible (intraclass correlation coefficient (ICC) $=0.93, \mathrm{p}<0.0001)$. Then, again, the limits of agreement between the two 6MWTs ranged from -67 to $120 \mathrm{~m}$. There was no correlation of the mean distance walked in the two 6MWTs on the improvement in the second test $(\mathrm{r}=-0.01$; $\mathrm{p}=0.61$ ).

A model of logistic regression showed that a higher odds ratio (OR) for a clinically important improvement of $\geqslant 42 \mathrm{~m}$ in the second 6MWT in comparison with the first 6MWT occurred in patients who had a poor first 6MWT $(<350 \mathrm{~m})(\mathrm{OR} 2.49 ; 95 \%$ CI 1.80-3.46; $\mathrm{p}<0.0001)$, patients without self-reported comorbidities other than COPD itself (OR 0.76; 95\% CI 0.58-0.99; $\mathrm{p}=0.043)$ and patients with BMI $<30 \mathrm{~kg} \cdot \mathrm{m}^{-2}$ (OR 0.60; 95\% CI $0.43-0.85 ; \mathrm{p}=0.004$ ) (table 2). Conversely, none of the studied patient characteristics was a determinant for decreasing the second 6MWT.

\section{Reproducibility of oxygen desaturation, fc and Borg symptom scores}

On average, the change in oxygen saturation during the first and second 6 MWTs was $-5.7 \%$ (95\% CI $-15-0 \%)$ and $-5.5 \%$ (95\% CI $-16-0 \%)$, respectively. The change in oxygen saturation was

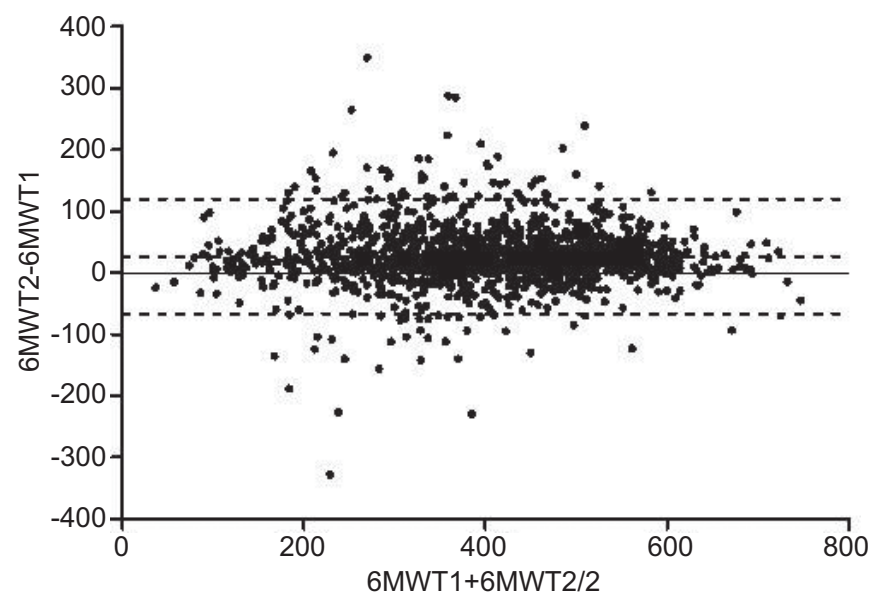

FIGURE 1. Bland and Altman plot of the difference between two 6-min walking tests (6MWTs) plotted against the mean value of the first (1) and second (2) 6MWT for the entire group of patients. The central dotted line corresponds to the average difference between two 6MWTs, whereas the lower and upper dotted lines correspond to lower and upper limits of agreement, respectively. 
TABLE 2 Relationship between patient characteristics and change in the walked distance in patients with chronic obstructive pulmonary disease

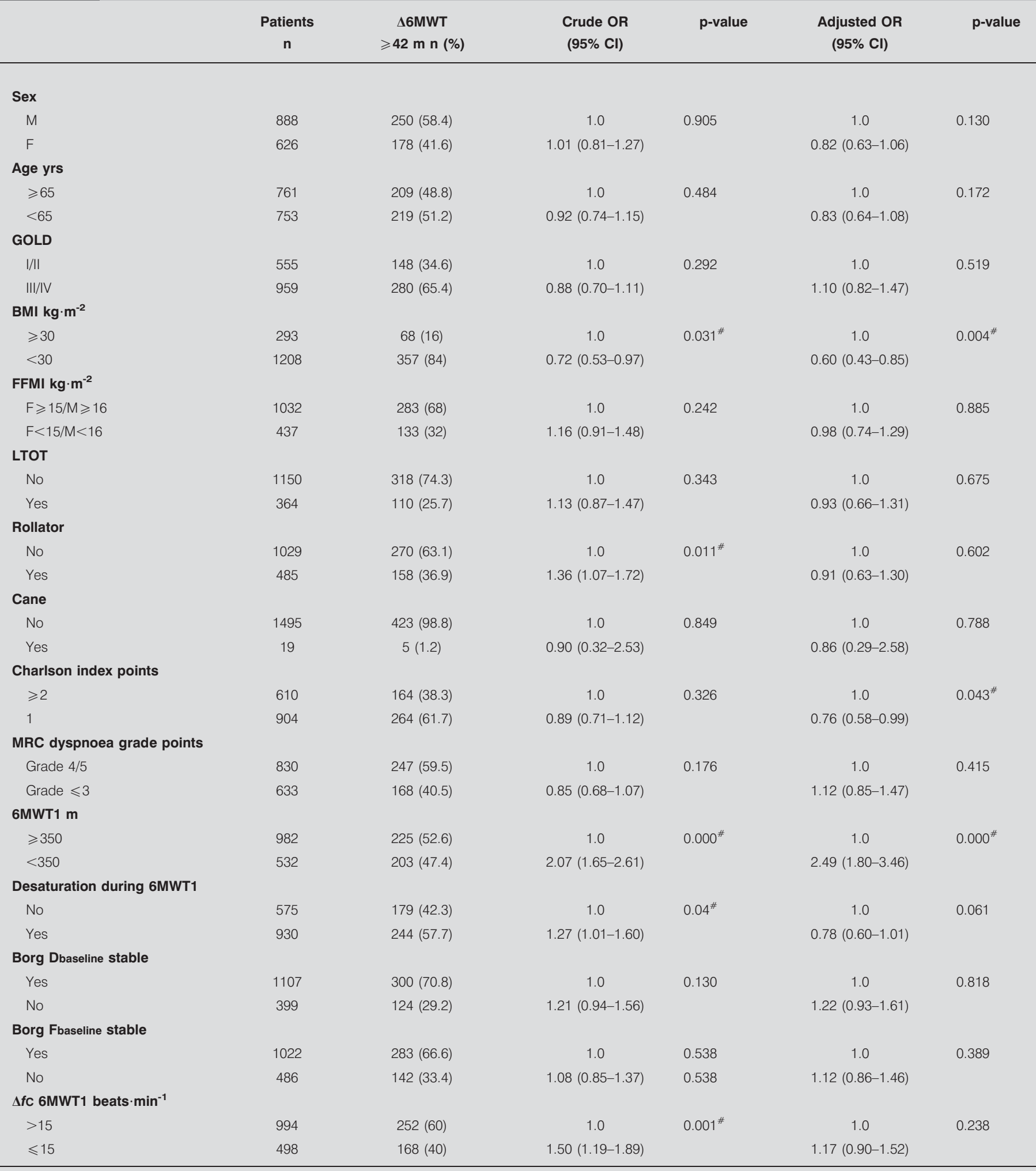

$\Delta$ : change in; 6MWT: 6-min walking test; M: male; F: female; GOLD: Global Initiative for Chronic Obstructive Lung Disease; BMI: body mass index; FFMl: fat-free mass index; LTOT: long-term oxygen therapy; MRC: Medical Research Council; T1: first test; Borg D: Borg dyspnoea scale; Borg F: Borg leg fatigue scale; fC: cardiac frequency. ${ }^{\#}: p \leqslant 0.05$ for all. 
reproducible $(\mathrm{ICC}=0.81, \mathrm{p}<0.0001)$. The Bland and Altman plot shows agreement between change in oxygen saturation during both $6 \mathrm{MWTs}$, with limits of agreement ranging from $-7 \%$ to $8 \%$ (fig. 2). Moreover, the sensitivity and specificity to detect oxygen desaturation during the second $6 \mathrm{MWT}$ based on oxygen desaturation during the first 6MWT were $80 \%$ and $77 \%$, respectively.

When comparing the change in $f C$, patients in GOLD stage IV had a lower change $\left(16 \pm 14\right.$ beats $\left.\cdot \mathrm{min}^{-1}\right)$ compared with GOLD I, II and III during the first test $(24 \pm 15,24 \pm 15$ and $22 \pm 14$ beats $\cdot \mathrm{min}^{-1}$, respectively; $\mathrm{p}>0.05$ for all) and during the second test $\left(18 \pm 13\right.$ beats $\mathrm{min}^{-1}$ versus $25 \pm 13,24 \pm 14$ and $22 \pm 14$ beats $\cdot \mathrm{min}^{-1}$, respectively; $\mathrm{p}>0.05$ for all). However, when taking into account the whole group, change in $f C$ during the first $6 \mathrm{MWT}$ was on average 21 beats $\cdot \mathrm{min}^{-1}(95 \%$ CI 0 46 beats $\left.\cdot \mathrm{min}^{-1}\right)$ and 21 beats $\cdot \mathrm{min}^{-1}\left(1-46\right.$ beats $\left.\cdot \mathrm{min}^{-1}\right)$ during the second $6 \mathrm{MWT}$. The reproducibility of change in $f C$ when two 6MWTs were performed was only modest $(\mathrm{ICC}=0.62$; $\mathrm{p}<0.0001)$.

Change in Borg dyspnoea score was 2.60 points (0-6 points) and 2.52 points ( $0-6$ points) during the first and second $6 \mathrm{MWT}$, respectively. In addition, the change in Borg leg fatigue score was 1.98 points ( $0-5$ points) during the first test and 2.01 points (0-6 points) during the second test. Once again, the reproducibility of change in Borg dyspnoea and leg fatigue score when two 6MWTs were performed was only modest (ICC $=0.59$ and $\mathrm{p}<0.0001$ for both).

\section{DISCUSSION}

This study examined the reproducibility of the 6MWT when two tests on subsequent days were performed in daily clinical practice in a large sample of patients with COPD entering pulmonary rehabilitation. Statistically, the 6MWT showed to be reproducible. However, a majority of patients increased the distance walked in the second test (mean change: $27 \mathrm{~m}$ or $7 \%$

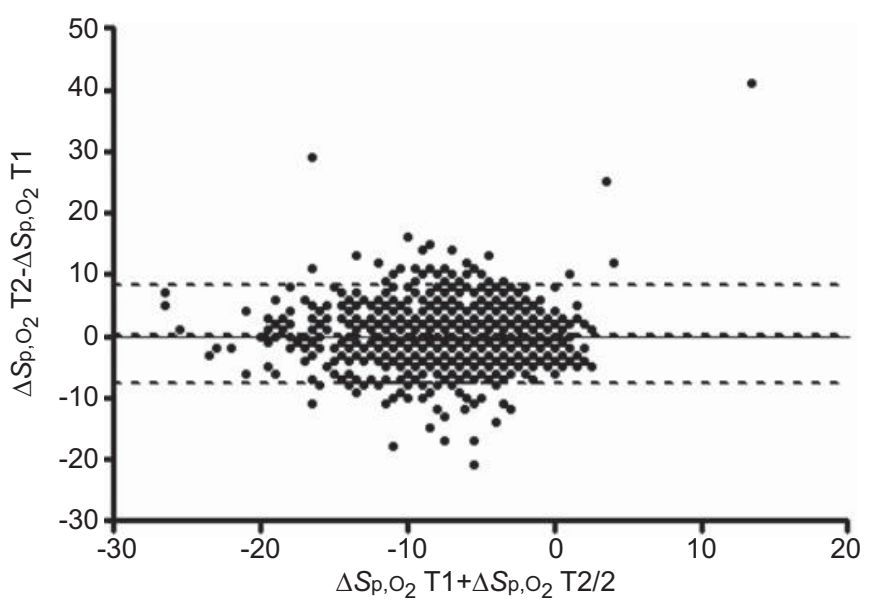

FIGURE 2. Bland and Altman plot of the difference between the change of arterial oxygen saturation measured by pulse oximetry $\left(\Delta \mathrm{Sp}, \mathrm{O}_{2}\right)$ during two 6-min walking tests (6MWTs) plotted against the mean value of the change of oxygen saturation during the first (1) and second (2) 6MWT for the entire group of patients. The central dotted line corresponds to the average difference between change of oxygen saturation during two 6MWTs, whereas the lower and upper dotted lines correspond to lower and upper limits of agreement, respectively. of the initial $6 \mathrm{MWT}$ ), suggesting that there is a considerable learning effect. The Bland and Altman analysis confirmed that the second 6MWT was better than the first, with limits of agreement largely exceeding $42 \mathrm{~m}$, which is considered the upper limit of a clinically important change in the 6MWT [7]. Furthermore, we determined that a poor first $6 \mathrm{MWT}(<350 \mathrm{~m})$, Charlson index $<2$ points or a BMI $<30 \mathrm{~kg} \cdot \mathrm{m}^{-2}$ are significant determinants of a clinically important change in the second $6 \mathrm{MWT}(\geqslant 42 \mathrm{~m})$ in comparison with the first 6MWT.

Various studies have reported a learning effect when repeated walking tests are performed in COPD. However, the results are controversial regarding the size of this learning effect. For example, Troosters et al. [17] found a learning effect of $2.6 \%$ in 20 patients with COPD who performed two 6MWTs in the same day. LEACH et al. [11] found that patients with COPD and interstitial lung disease increased $8.6 \%$ the distance walked when two 6MWTs were performed in the same day. STEVENS et al. [18] demonstrated a learning effect of $\sim 10 \%$ in patients with advanced lung disease who were participants of a pulmonary rehabilitation programme. SPENCER et al. [19] found a $7 \%$ improvement in the second 6MWT in patients with COPD, which is in accordance with our findings. SCIURBA et al. [10] also found an increase of $7 \%$ when two 6MWTs were performed. However, they included only patients with severe and very severe COPD. Besides the heterogeneity in the learning effect size, those studies often included patients with COPD and patients with other lung diseases [11, 13, 18] or only patients with severe disease [10], and this could compromise the external validity of their findings. Moreover, the majority of studies did not show the limits of agreement between the walking distance assessments, compromising the interpretation of the results and their internal validity [10, 18-20].

The clinical implication of our findings is evident as the disagreement between two 6MWTs can influence interpretation of the performance in the test. Our results demonstrated that $82 \%$ of patients walked further in the second $6 \mathrm{MWT}$, meaning that the vast majority of patients entering into a pulmonary rehabilitation programme could have an incorrect conclusion about their functional exercise capacity if only one test was performed. Indeed, we have found that a poor first $6 \mathrm{MWT}$, a score of $<2$ points on the Charlson index and nonobesity are significant determinants of a change in 6MWT $\geqslant 42 \mathrm{~m}$. Therefore, incorrect exercise training workloads may be applied during exercise training in case of only one baseline 6MWT. Furthermore, this disagreement can be clinically relevant as the 6MWT has been widely used as a predictor of morbidity and mortality in patients with COPD. For example, the proportion of patients who had a poor $6 \mathrm{MWT}(<350 \mathrm{~m})$ decreased when the best of two walked distances was considered for analysis in our sample (35\% versus $28 \%$ ). It shows that, at the first test, $7 \%$ of patients had a false poor walked distance detected. Therefore, it is recommended that at least two 6MWT are performed in clinical settings.

In our study, we also found that the change in oxygen saturation during the 6MWT was reproducible. Moreover, its sensitivity and specificity were 0.80 and 0.77 , respectively. These findings are interesting for clinical practice as the 6MWT has been used to determine the need for oxygen ambulatory prescription in patients with COPD and results about its 
reproducibility are controversial. Poulain et al. [30] found that oxygen desaturation, defined as a fall of $\geqslant 4 \%$ of resting $\mathrm{S}_{\mathrm{p}, \mathrm{O}_{2}}$ value during at least $3 \mathrm{~min}$, was reproducible when three 6MWTs were performed in 10 patients with COPD. In contrast, CHATTERJEe et al. [15] demonstrated that the 6MWT oxygen saturation has only modest reproducibility in determining the need for ambulatory oxygen ( $\mathrm{Sp}, \mathrm{O}_{2} \leqslant 88 \%$ during at least $5 \mathrm{~s}$ ) in stable COPD patients actively participating in a pulmonary rehabilitation programme when three 6MWTs were performed ( $\kappa$ statistic $=0.62,72 \%$ of agreement between measurements).

\section{Strengths, limitations and future perspectives}

Although some authors have already studied the reproducibility of the $6 \mathrm{MWT}$, our study raises several points that strengthen the trustworthiness of our findings. First, the present sample $(n=1,514)$ was undoubtedly representative of a COPD population and comprised of patients with different levels of disease severity. Secondly, the statistical analysis produced results of clinical importance as not only average data were described, but also limits of agreement between assessments. Furthermore, some methodological strategies were carefully provided to ensure results reliability: the same walking course was always used, avoiding influence of length and layout track on the walked distance [10]; tests were performed at the same period of the day; encouragement and instructions were standardised and supervisors were familiarised with the 6MWT [6]; and patients who had previously participated in rehabilitation programmes were not included in the study. However, some limitations occurred. First, some variables that can influence the improvement of the second 6MWT, such as anxiety, depression and balance, were not studied [5]. Secondly, the tests were not always executed by the same supervisor; however, as previously mentioned, all supervisors were strongly familiarised with the 6MWT standardisation. In addition, the present results are only applicable to 6MWT performed before a pulmonary rehabilitation programme and on subsequent days.

\section{Conclusion}

In summary, the 6MWT was reproducible in a large and representative sample of patients with COPD. However, the vast majority of patients increased their second $6 \mathrm{MWT}$, presenting a learning effect of $27 \mathrm{~m}(7 \%)$ and with limits of agreement that largely exceed the minimal clinical difference. A poor performance in the first 6MWT, combined with few comorbidities and non-obesity, were the most relevant determinant factors for a change between the first and second tests that exceeds the clinical importance. Standardisation of the 6MWT and at least two tests are necessary to avoid incorrect assessment of functional exercise capacity.

\section{SUPPORT STATEMENT}

N.A. Hernandes was a recipient of a European Respiratory Society short-term fellowship (grant number: 634).

\section{STATEMENT OF INTEREST}

None declared.

\section{ACKNOWLEDGEMENTS}

We acknowledge the support of the European Respiratory Society, Fellowship number 634.

\section{REFERENCES}

1 Rabe KF, Hurd S, Anzueto A, et al. Global strategy for the diagnosis, management, and prevention of chronic obstructive pulmonary disease: GOLD executive summary. Am J Respir Crit Care Med 2007; 176: 532-555.

2 Pitta F, Troosters T, Spruit MA, et al. Characteristics of physical activities in daily life in chronic obstructive pulmonary disease. Am J Respir Crit Care Med 2005; 171: 972-977.

3 Spruit MA, Pennings HJ, Janssen PP, et al. Extra-pulmonary features in COPD patients entering rehabilitation after stratification for MRC dyspnea grade. Respir Med 2007; 101: 2454-2463.

4 Palange P, Ward SA, Carlsen K-H, et al. Recommendations on the use of exercise testing in clinical practice. Eur Respir J 2007; 29: 185-209.

5 Spruit MA, Watkins ML, Edwards LD, et al. Determinants of poor 6-min walking distance in patients with COPD: the ECLIPSE cohort. Respir Med 2010; 104: 849-857.

6 ATS statement: guidelines for the six-minute walk test. Am J Respir Crit Care Med 2002; 166: 111-117.

7 Puhan MA, Mador MJ, Held U, et al. Interpretation of treatment changes in 6-minute walk distance in patients with COPD. Eur Respir J 2008; 32: 637-643.

8 Cazzola M, MacNee W, Martinez FJ, et al. Outcomes for COPD pharmacological trials: from lung function to biomarkers. Eur Respir J 2008; 31: 416-469.

9 Pinto-Plata VM, Cote C, Cabral H, et al. The 6-min walk distance: change over time and value as a predictor of survival in severe COPD. Eur Respir J 2004; 23: 28-33.

10 Sciurba F, Criner GJ, Lee SM, et al. Six-minute walk distance in chronic obstructive pulmonary disease: reproducibility and effect of walking course layout and length. Am J Respir Crit Care Med 2003; 167: 1522-1527.

11 Leach RM, Davidson AC, Chinn S, et al. Portable liquid oxygen and exercise ability in severe respiratory disability. Thorax 1992; 47: 781-789.

12 Iriberri M, Galdiz JB, Gorostiza A, et al. Comparison of the distances covered during 3 and 6 min walking test. Respir Med 2002; 96: 812-816.

13 Guyatt GH, Pugsley SO, Sullivan MJ, et al. Effect of encouragement on walking test performance. Thorax 1984; 39: 818-822.

14 Eiser N, Willsher D, Dore CJ. Reliability, repeatability and sensitivity to change of externally and self-paced walking tests in COPD patients. Respir Med 2003; 97: 407-414.

15 Chatterjee AB, Rissmiller RW, Meade K, et al. Reproducibility of the 6-minute walk test for ambulatory oxygen prescription. Respiration 2010; 79: 121-127.

$16 \mathrm{Wu} \mathrm{G}$, Sanderson B, Bittner V. The 6-minute walk test: how important is the learning effect? Am Heart J 2003; 146: 129-133.

17 Troosters T, Vilaro J, Rabinovich R, et al. Physiological responses to the 6-min walk test in patients with chronic obstructive pulmonary disease. Eur Respir J 2002; 20: 564-569.

18 Stevens D, Elpern E, Sharma K, et al. Comparison of hallway and treadmill six-minute walk tests. Am J Respir Crit Care Med 1999; 160: 1540-1543.

19 Spencer LM, Alison JA, McKeough ZJ. Six-minute walk test as an outcome measure: are two six-minute walk tests necessary immediately after pulmonary rehabilitation and at three-month follow-up? Am J Phys Med Rehabil 2008; 87: 224-228.

20 Rodrigues SL, Mendes HF, Viegas CAA. Six minute walk test: study of the effect of learning in chronic obstructive pulmonary disease patients. Rev Port Pneumol 2004; 30: 121-125.

21 Spruit MA, Wouters EF. New modalities of pulmonary rehabilitation in patients with chronic obstructive pulmonary disease. Sports Med 2007; 37: 501-518.

22 van Stel HF, Bogaard JM, Rijssenbeek-Nouwens LH, et al. Multivariable assessment of the 6-min walking test in patients with chronic obstructive pulmonary disease. Am J Respir Crit Care Med 2001; 163: 1567-1571. 
23 Troosters T, Gosselink R, Decramer M. Six minute walking distance in healthy elderly subjects. Eur Respir J 1999; 14: 270-274.

24 Quanjer PH, Tammeling GJ, Cotes JE, et al. Lung volumes and forced ventilatory flows. Report Working Party Standardization of Lung Function Tests, European Community for Steel and Coal. Official Statement of the European Respiratory Society. Eur Respir J 1993; 6: Suppl. 16, 5-40.

25 Knudson RJ, Burrows B, Lebowitz MD. The maximal expiratory flow-volume curve: its use in the detection of ventilatory abnormalities in a population study. Am Rev Respir Dis 1976; 114: 871-879.

26 Graat-Verboom L, Spruit MA, van den Borne BE, et al. Correlates of osteoporosis in chronic obstructive pulmonary disease: an underestimated systemic component. Respir Med 2009; 103: 1143-1151.
27 Schols AM, Soeters PB, Dingemans AM, et al. Prevalence and characteristics of nutritional depletion in patients with stable COPD eligible for pulmonary rehabilitation. Am Rev Respir Dis 1993; 147: 1151-1156.

28 Celli BR, Cote CG, Marin JM, et al. The body-mass index, airflow obstruction, dyspnea, and exercise capacity index in chronic obstructive pulmonary disease. N Engl J Med 2004; 350: 1005-1012.

29 Charlson M, Szatrowski TP, Peterson J, et al. Validation of a combined comorbidity index. J Clin Epidemiol 1994; 47: 1245-1251.

30 Poulain M, Durand F, Palomba B, et al. 6-minute walk testing is more sensitive than maximal incremental cycle testing for detecting oxygen desaturation in patients with COPD. Chest 2003; 123: 1401-1407. 